\title{
Cytarabine Hydrochloride
}

National Cancer Institute

\section{Source}

National Cancer Institute. Cytarabine Hydrochloride. NCI Thesaurus. Code C71603.

The hydrochloride form of cytarabine, an antimetabolite analogue of cytidine with a modified sugar moiety (arabinose instead of ribose). Cytarabine is converted to the triphosphate form within the cell and then competes with cytidine for incorporation into DNA. Because the arabinose sugar sterically hinders the rotation of the molecule within DNA, DNA replication ceases, specifically during the $S$ phase of the cell cycle. This agent also inhibits DNA polymerase, resulting in a decrease in DNA replication and repair. 